\title{
Modeling Stress-Dependent Anisotropic Elastoplastic Unbound Granular Base in Flexible Pavements ${ }^{1}$
}

\author{
Yuqing Zhang, Ph.D. \\ Lecturer \\ Aston Institute of Materials Research, and \\ Engineering System \& Management Group \\ School of Engineering and Applied Science \\ Aston University \\ Aston Triangle, Birmingham, B4 7ET, U.K. \\ Phone: +44 (0) 121-204-3391, Email: y.zhang10@aston.ac.uk \\ (Corresponding author)
}

Fan Gu, Ph.D.

Postdoctoral Researcher

National Center for Asphalt Technology

Auburn University

277 Technology Parkway, Auburn, AL 36830

Phone: (334)-844-6251, Email: $\underline{\text { fzg0014@ auburn.edu }}$

Xue Luo, Ph.D.

Associate Research Scientist

Center for Infrastructure Renewal

Texas A\&M University System

3135 TAMU, CEOB 508B, College Station, Texas 77843

Phone: (979) 458-8535, Email: xueluo@tamu.edu

Bjorn Birgisson, Ph.D., P.E.

Distinguished Research Professor and Director

Center for Infrastructure Renewal (CIR)

Texas A\&M University System

3136 TAMU, DLEB Bldg. 503E, College Station, Texas 77843

Phone: +1 (979) 845-6039, Email: bjorn.birgisson@tamu.edu

Robert L. Lytton, Ph.D., P.E.

Professor, Fred J. Benson Chair

Zachry Department of Civil Engineering

Texas A\&M University

3136 TAMU, DLEB Bldg. 503A, College Station, Texas 77843

Phone: (979) 845-9964, Email: r-lytton@ civil.tamu.edu

\footnotetext{
${ }^{1}$ This is an Accepted Manuscript of an article published by Transportation Research Record: Journal of the Transportation Research Board. The final publication is available online via https://doi.org/10.1177/0361198118758318
} 


\begin{abstract}
Unbound granular base (UGB) has a cross-anisotropic and nonlinear (stress-dependent) modulus with a plastic behavior. Existing UGB models address nonlinear cross-anisotropy and plasticity separately. It is unknown how the two characteristics are coupled into a finite element model (FEM) and how this will affect the pavement responses. This study presents a coupled nonlinear cross-anisotropic elastoplastic (NAEP) constitutive model for the UGB and implements it in a weak form equation-based FEM. No material subroutine is needed to address the circular dependence between the stress-dependent anisotropic modulus, structural stress responses and elastoplastic deformation. The NAEP model was calibrated by triaxial resilient modulus and strength tests and validated using laboratory measurements in a large-scale soil-tank pavement structural test. It is found that the NAEP model is valid and effective in predicting the UGB responses in flexible pavements. The model predicted less horizontal tensile stresses at the base bottom and introduced compressive stresses in the middle and top of the base course. This is caused by an increasing confinement resulting from a horizontal plastic dilation in the base course, which cannot be modeled without considering plasticity. The stress-dependent modulus for the UGB material decreases with depth and the distance from loading centerline. Compared to a nonlinear anisotropic elastic model, the NAEP model predicted the same tensile strain at asphalt layer bottom, a higher base modulus and a higher subgrade compressive strain. Thus the nonlinear anisotropic elastic UGB model results in the same fatigue life as the NAEP model, but may riskily under-predict the rutting damage.
\end{abstract}




\section{INTRODUCTION}

An unbound granular base (UGB) provides the foundational support to a flexible pavement and distribute the stresses induced by traffic load to the underlying subgrade. Understanding the constitutive behavior of the UGB materials is crucial to the accurate performance prediction of the pavement structures. In the current pavement design, the UGB material is assumed as a linear (stress-independent) elastic material. The linear isotropic model predicted unexpected and high tensile stresses at the bottom of the base course, which cannot be sustained by the UGB material in reality. A number of studies have revealed that the UGB material exhibits a nonlinear cross-anisotropic behavior, which means that the modulus of the UGB is stress-dependent (nonlinearity) and the elastic material properties (modulus and Poisson's ratio) in the vertical plane differ from those in the horizontal plane (cross-anisotropy). For example, Tutumluer and Seyhan (1), Adu-Osei et al. (2) and Gu et al. (3) successfully determined the nonlinear cross-anisotropic properties of the UGB using triaxial resilient modulus test at different stress states. Tutumluer and Thompson developed a finite element program to model the nonlinear cross-anisotropic behavior of UGB in flexible pavements (4). They found that a nonlinear cross-anisotropic model predicted much less horizontal tensile stresses in base course compared to the linear elastic model. A residual compressive stress of $21 \mathrm{kPa}$ resulting from compaction was suggested to compensate the tensile stresses, leading to a compressive horizontal stress in the base course. Oh et al. (5) and Al-Qadi et al. (6) reported that modeling the pavement structures using a nonlinear cross-anisotropic approach predicted greater pavement responses including tensile strain at the bottom of asphalt layer and compressive strain on top of subgrade than a linear model. Tutumluer et al. (7) and Wang and Al-Qadi (8) concluded that the nonlinear cross-anisotropic model provided better agreement with the field measurements. Hence, modeling UGB as a nonlinear cross-anisotropic material should be taken into account for the pavement performance predictions.

However, some studies also demonstrated that, when subjected to a heavy load, the UGB material exhibits a significant plastic behavior in addition to the stress-dependent anisotropic behavior in flexible pavements $(9,10)$. Even at a low load level, the responses of a UGB still include the recoverable and unrecoverable strains (11). The recoverable strain is characterized by the nonlinear anisotropic resilient behavior of UGB, while the unrecoverable strain is reflected by the plastic behavior of UGB. Currently, few studies have been able to simultaneously model the nonlinear stress-dependence, cross-anisotropy and plastic behavior of the UGB materials. No studies have implemented a coupled nonlinear anisotropic elastoplastic model for UGB in a numerical program to evaluate the material responses and pavement performance. The potential reasons include: 1) a circular dependence exists between UGB material properties (anisotropic modulus), stress distribution in pavement and the evolution of strains including elastic and plastic strains, which has not been well understood; 2) programming and utilizing a material subroutine in a finite element model to solve the circular dependence is very complicated and timeconsuming due to the issues such as high nonlinearity, low-efficient iteration and none-convergence, requiring significant training and knowledge of numerical programming for the ultimate users; and 3) difficulties exist in determining model coefficients using effective and efficient laboratory tests.

This study aims to characterize the UGB's cross-anisotropic, nonlinear and plastic properties simultaneously using a nonlinear anisotropic elastoplastic (NAEP) model. The NEAP model is then implemented in a weak form equation-based finite element modeling to demonstrate how the circular dependence is effectively modeled without a need of a material subroutine. The NAEP model is validated by pavement structural loading tests in a laboratory large-scale tank. The distribution of stress-dependent modulus, horizontal stress and plastic strain in the base course are also evaluated by comparing the NAEP model predictions with the predictions from linear (and nonlinear) anisotropic elastic models. Critical pavement responses are also determined by various UGB models to evaluate the effects of NAEP model on the flexible pavement performance. 


\section{ANISOTROPIC NONLINEAR ELASTOPLASTIC CONSTITUTIVE MODEL FOR UGB Cross-Anisotropy of UGB Materials}

A well-established cross-anisotropic constitutive model is employed for the UGB materials, as shown in Equation 1, where the z-axis is the axis of symmetry (12). Thus the UGB is anisotropic in z-x and z-y planes and becomes isotropic in the $\mathrm{x}-\mathrm{y}$ plane.

$$
\left[\begin{array}{c}
\sigma_{x x} \\
\sigma_{y y} \\
\sigma_{z z} \\
\sigma_{x y} \\
\sigma_{y z} \\
\sigma_{z x}
\end{array}\right]=\frac{E_{z}}{\alpha_{0} \beta_{0}}\left[\begin{array}{cccccc}
n\left(1-n v_{z x}^{2}\right) & n\left(v_{x y}+n v_{z x}^{2}\right) & n v_{z x} \alpha_{0} & 0 & 0 & 0 \\
n\left(v_{x y}+n v_{z x}^{2}\right) & n\left(1-n v_{z x}^{2}\right) & n v_{z x} \alpha_{0} & 0 & 0 & 0 \\
n v_{z x} \alpha_{0} & n v_{z x} \alpha_{0} & 1-v_{x y}^{2} & 0 & 0 & 0 \\
0 & 0 & 0 & \frac{1}{2} n \beta_{0} & 0 & 0 \\
0 & 0 & 0 & 0 & m \alpha_{0} \beta_{0} & 0 \\
0 & 0 & 0 & 0 & 0 & m \alpha_{0} \beta_{0}
\end{array}\right]\left[\begin{array}{c}
\varepsilon_{x x} \\
\varepsilon_{y y} \\
\varepsilon_{z z} \\
2 \varepsilon_{x y} \\
2 \varepsilon_{y z} \\
2 \varepsilon_{z x}
\end{array}\right]
$$

where $\sigma_{i j}=$ stress tensor; $\varepsilon_{i j}=$ strain tensor; and $i, j=x, y, z ; n=E_{x} / E_{z} ; m=G_{z x} / E_{z} ; \alpha_{0}=1+v_{x y}$; $\beta_{0}=1-v_{x y}-2 n v_{z x}^{2} ; E_{x}=$ horizontal modulus in x-direction; $E_{z}=$ vertical modulus in z-direction; $G_{z x}$ $=$ shear modulus in the vertical $(\mathrm{z}-\mathrm{x})$ plane; $v_{x y}=$ Poisson's ratio in the horizontal $(\mathrm{x}-\mathrm{y})$ plane, characterizing the effect of a horizontal strain (x-direction) on the orthogonal horizontal strain (ydirection); $v_{z x}=$ Poisson's ratio in the vertical ( $\left.\mathrm{z}-\mathrm{x}\right)$ plane, characterizing the effect of the vertical strain (z-direction) on the horizontal strain (x-direction). Note that $E_{x}, E_{z}, v_{x y}, v_{z x}$, and $G_{z x}$ are the five independent material properties characterizing the cross-anisotropic behavior of the UGB. In Equation 1, the five independent material properties are represented by $E_{z}, n, m, \alpha_{0}$ and $\beta_{0}$.

\section{Stress-Dependent Nonlinearity of UGB}

The vertical modulus of the UGB is modeled by a nonlinear stress-dependent model as below (13).

$$
E_{z}=k_{1} P_{a}\left(\frac{I_{1}}{P_{a}}\right)^{k_{2}}\left(\frac{\tau_{o c t}}{P_{a}}\right)^{k_{3}}
$$

where $I_{1}=\sigma_{k k}$ is the first invariant of the stress tensor, $\sigma_{i j} ; P_{a}=$ the atmospheric pressure, $101.3 \mathrm{kPa}$; $\tau_{o c t}=\sqrt{S_{i j} S_{i j} / 3}=\sqrt{2 J_{2} / 3}$ is the octahedral shear stress; $S_{i j}=$ the deviatoric stress tensor and $S_{i j}=\sigma_{i j}-1 / 3 \sigma_{k k} \delta_{i j}$ where $\delta_{i j}$ is the Kronecker delta, and $k_{1}, k_{2}$ and $k_{3}=$ regression coefficients to be determined by laboratory tests. Note that the horizontal modulus becomes stress dependent as well by the relationship of $n=E_{x} / E_{z}$ that is used in Equation 1 .

\section{Elastoplastic Models for UGB}

A Generalized Drucker-Prager (GD-P) yield surface model was developed by the authors to allow a smooth and convex yield surface when frictional angle varies from 0 to 90 degrees for granular materials such as asphalt, aggregate base, sand or soil materials (14). This GD-P model can remove the inherent limitations of the existing models, e.g., the non-smoothness for the Mohr-Coulomb yield surface or the 
non-convexity for the extended Drucker-Prager yield surface when the frictional angle is greater than 22 degrees. Furthermore, the GD-P model can be reduced to Drucker-Prager model (when parameter $d=1$ ) or Matsuoka-Nakai model (when parameter $\kappa=0$ ), which have been extensively used for modeling the yield surface of the granular materials. The GD-P model is expressed as:

$$
f=\sqrt{J_{2}} \rho\left(\theta^{\prime}\right)-\alpha I_{1}-\kappa
$$

where $J_{2}=1 / 2 S_{i j} S_{i j}$ is the second invariant of the deviatoric stress tensor; $\theta^{\prime}=$ Lode angle that is defined as:

$$
\theta^{\prime}=\frac{1}{3} \arccos \left[\frac{3 \sqrt{3}}{2} \frac{J_{3}}{\left(J_{2}\right)^{3 / 2}}\right]
$$

where $J_{3}=\operatorname{det}\left(S_{i j}\right)$ is the third invariant of the deviatoric stress tensor. $\theta^{\prime}$ is zero for compression and $\pi / 3$ for extension. $\rho\left(\theta^{\prime}\right)=$ a function defining the yield surface shape on the octahedral plane and determining the convexity of the yield surface, which is expressed as:

$$
\rho\left(\theta^{\prime}\right)=\mu \cos \left[\frac{1}{3} \arccos \left(\gamma \cos 3 \theta^{\prime}\right)\right]
$$

where $\mu$ and $\gamma=$ parameters determining the size and shape of the yield surface on the octahedral plane, respectively, to ensure a smooth and convex yield surface. They are fundamentally related to material friction angle as:

$$
\mu=\frac{2 \sqrt{1-d+d^{2}}}{\sqrt{3} d}, \gamma=-\frac{3 \sqrt{3}}{2} \frac{(1-d) d}{\left(1-d+d^{2}\right)^{1.5}}, \quad d=\frac{3-\sin \phi}{3+\sin \phi}
$$

where $d=$ extension ratio that is the ratio of the yield strength in extension to that in compression. $\phi=$ internal friction angle, which also directly determines the slope of the yield surface on a meridian plane by:

$$
\alpha=\frac{2 \sin \phi}{\sqrt{3}(3-\sin \phi)}
$$

The parameter $\kappa$ in the GD-P model represents the material cohesion characteristic and can be determined by material cohesion $(C)$ and internal friction angle $(\phi)$ :

$$
\kappa=\frac{6 C \cos \phi}{\sqrt{3}(3-\sin \phi)}
$$

It is noted that a yielding end-cap surface can be added to the GD-P model to address the yield surface softening at a high hydrostatic pressure, which is not considered in this study due to that a limited confining pressure will be achieved in base course, as shown in the result analysis. The increment of the plastic strain of the UGB occurs when the current state of the stress satisfies the yield surface function (i.e., $f=0$ ). With hypothesizing small plastic strain, the direction of the plastic strain increment is defined by a non-associated plastic flow rule: 


$$
\dot{\varepsilon}_{i j}^{p}=\lambda \frac{\partial g}{\partial \sigma_{i j}}
$$

where $\dot{\varepsilon}_{i j}^{p}=$ the rate at which the plastic strain changes with respect to $\partial g / \partial \sigma_{i j} ; \lambda$ is a plastic multiplier which depends on the current state of stress and the load history. $\lambda$ is determined by the complementarity or Kuhn-Tucker conditions:

$$
\lambda \geq 0, f \leq 0 \text { and } \lambda f=0
$$

The variable $g$ in the plastic flow rule is a plastic potential function. The non-associated flow rule applies when $g \neq f$, which is appropriate for shear dilating granular materials such as asphalt, UGB and soils. It is demonstrated that the plastic potential surface has the same linear form as the yield surface but with a smaller slope which affects the volumetric dilation of the material:

$$
g=\sqrt{J_{2}} \rho\left(\theta^{\prime}\right)-\beta I_{1}
$$

A number of studies have indicated that $\beta<\alpha$ is valid for geo-materials such as soils, sands, and asphalt mixtures $(15,16) . \beta$ is derived to be a function of anisotropy (14):

$$
\beta=0.5889 \Delta^{\prime}-0.0122
$$

where $\Delta^{\prime}$ is a microstructural parameter quantifying anisotropy of the UGB that can be determined by (17):

$$
\Delta^{\prime}=\frac{3 \sqrt{1 / n}-3}{4-\sqrt{1 / n}}
$$

where $n$ is defined as the anisotropic modulus ratio and $n=E_{x} / E_{z}$ that is used in Equation 1. Equations 12 and 13 were originally derived for asphalt mixtures however it still applies to the UGB. This is because the inherent anisotropy of both asphalt mixtures and UGB are caused by the preferentially oriented aggregate particles in the horizontal directions and can be quantified by the microstructural parameter using the same model $(17,18)$. The validation of the UGB plastic responses by laboratory tests in this study will also verify the applicability of the models for the UGB materials.

\section{EXPERIMENTS AND MATERIAL CHARACTERISATION \\ Flexible Pavement Structures and Models}

Table 1 summaries the structure of a flexible pavement to be modeled including the layer thickness, materials, their constitutive models and corresponding parameter determination methods. The flexible pavement consists of three layers, namely, $15 \mathrm{~cm}$ asphalt course, $25 \mathrm{~cm}$ base course and $140 \mathrm{~cm}$ subgrade. The layer thickness was obtained based on a laboratory large-sale tank test. The asphalt concrete is modeled as a viscoelastic material. To evaluate the pavement responses predicted by different UGB constitutive models, the UGB materials are modeled as a nonlinear anisotropic elastoplastic (NAEP) model, a nonlinear anisotropic elastic (NAE) model and a linear anisotropic elastic (LAE) model, 
respectively. The subgrade is modeled as an elastic material and its elastic modulus is estimated based on California bearing ratio test (19).

\section{Asphalt Concrete Characterization}

In this study, the asphalt concrete is modeled as a viscoelastic material. A solid-like generalized Maxwell model is used to model the material's relaxation modulus (20):

$$
E(t)=E_{\infty}+\sum_{i=1}^{M} E_{i} \exp \left(-\frac{t}{\tau_{i}}\right)
$$

where $E_{\infty}=$ long-term equilibrium modulus; $E_{m}=$ components of the relaxation modulus; $\tau_{m}=$ components of relaxation time; $t=$ time and $M=$ the total number of the Maxwell elements (one Maxwell element is composed of one elastic spring and one viscous dashpot connected in series). Dynamic modulus tests following ASTM standard (21) were employed to determine the dynamic modulus and phase angle of the asphalt concrete, which are then used to determine the coefficients in the generalized Maxwell model of the relaxation modulus according to a conversion method presented previously (22). Note that a constant Poisson's ratio was assumed for the asphalt concrete to simplify the simulation though it is a time-dependent variable as well (23). The determined Maxwell model coefficients for the asphalt concrete are shown in Table 2.

\section{Unbound Granular Base Material Characterization}

Granite crushed aggregates are used to construct the base course. The aggregate gradation and physical properties can be found in a previous study (11). It has a maximum dry density of $2.16 \times 10^{3} \mathrm{~kg} / \mathrm{m}^{3}$ and an optimum water content of $6.7 \%$. Repeated load triaxial tests were performed on the cylindrical aggregate specimens using a universal testing machine (UTM) with a rapid triaxial test (RaTT) cell to determine the cross-anisotropic stress dependent resilient modulus of the UGB. A test protocol with ten stress states (with different axial stresses and confining pressures) were used to produce three stress modes (compression, shear and extension) in the specimen (2). At each stress state, every loading cycle of the dynamic stress consisted of 1.5 seconds of loading and 1.5 seconds of unloading. The vertical and horizontal deformations of the specimen were recorded to calculate the anisotropic properties of the aggregate specimen using systematic identification method and the results are presented in Table 2 .

A triaxial compressive strength test was used to determine the shearing resistance of the base materials according to Tex-117-E (24). The axial load was applied at a constant strain rate of $2 \%$ on the UGB specimen under three confining pressures (i.e., 0, 20.7 and $103.4 \mathrm{kPa}$ ) until the specimen collapsed. The initial yielding stress was identified from the curve of deviatoric stress and axial strain at a specific confining pressure. Then the material cohesion and friction angle were determined based on Mohr's yielding envelope to be $20.2 \mathrm{kPa}$ and $51.3^{\circ}$, respectively. Details of the UGB material characterization and model coefficient determination can be found in the literature $(11,25)$. The NAE model parameters remain unchanged from the NAEP model except that the plastic model component was disabled. The LAE model parameters remain unchanged from the NAE except that a constant vertical modulus of 150 MPa was used based on the average vertical modulus of the NAE predictions.

\section{FINITE ELEMENT MODELING OF UGB IN FLEXIBLE PAVEMENTS Weak form equation-based finite element modeling in Comsol program}

The viscoelastic constitutions of asphalt concrete have been successfully modeled using a weak-form partial differential equation (PDE) based finite element (FE) modelling technique in Comsol Multiphysics program (22). The viscoplastic and viscofracture properties of the asphalt concrete have also been coupled in the viscoelastic constitutive models based on the weak-form PDE based FE method (26). It demonstrates that accurate viscoelastic and viscoplastic responses can be modeled and predicted for the 
asphalt concrete. Unlike using Abaqus, there is no need for this method to program a user-defined material subroutine. In this study, the authors continue modeling the asphalt concrete using the PDE-FE method while only considering its viscoelastic responses, details of which are referred to the above two publications $(22,26)$.

The weak-form PDE-FE is particularly advantageous in solving a coupling problem with circular dependence between the model inputs and the dependent variables to be solved. Modeling a UGB material with a stress-dependent modulus is a typical coupling problem which involves a circular dependence between modulus, stress and deformation. This circular dependence can be broken by creating two additional Dependent Variables (DVs) in the weak-form PDE-FE modelling to define the stress-dependent modulus. The two DVs will be defined in Weak Expressions and solved simultaneously with the other three defined DVs (i.e., displacement components in spatial x-, y-and z- directions). Specifically, the below modelling steps are followed. Note a bold and italic expression represents a module or a defined variable in the Comsol program

Step 1. Define the material properties from Table 2 as Parameters to be used as model inputs or to define variables.

Step 2. Create a new physics using Weak Form PDE module and define its two Dependent Variables as $\boldsymbol{u} 11$ and $\boldsymbol{u 1 2}$ with a unit of $\mathrm{N} / \mathrm{m}^{2}$. In addition, global DVs have been defined for the UGB materials using a Linear Elastic Material module that includes the displacement components in three directions, i.e., $u, v$, and $w$.

Step 3. Define the constitutive equation for the dependent variables in Weak Expressions as below and Comsol will perform a numerical integration of the Weak Expressions over a volumetric region (e.g., the FE model of the base course) and find the solutions for all DVs.

$$
\left\{\begin{array}{l}
-(u 11-\text { solid.I1s }) * \text { test }(u 11) \\
-(u 12-\operatorname{sqrt}(\text { solid.II } 2 s * 2 / 3)) * \operatorname{test}(u 12)
\end{array}\right.
$$

where solid.IIs and solid.II $2 \mathrm{~s}$ are respectively the first invariant of the stress tensor $\left(I_{1}\right)$ and the second invariant of the deviatoric stress tensor $\left(J_{2}\right)$, which are pre-defined by Comsol and can be directly used in the weak expressions.

Step 4. Define the stress-dependent vertical modulus of the UGB as a Variable using the DVs as below.

$$
E_{Z}=k_{1} * P_{a} *\left(a b s(u 11) / P_{a}\right)^{\wedge} k_{2} *\left(u 12 / P_{a}\right)^{\wedge} k_{3}
$$

Note that $\boldsymbol{u 1 1}$ is always negative for the UGB materials as the first stress invariant in the base course is always in compression and Comsol defines compression as negative. Thus an absolute value of $\boldsymbol{u} 11$ is used to calculate the stress-dependent vertical modulus. $k_{1}, k_{2}, k_{3}$ and $P_{a}$ are Parameters defined in Step 1.

Step 5. Employ the variable $E_{Z}$ in the Linear Elastic Material module for the UGB material together with other cross-anisotropic model parameters defined in Step 1 as the model inputs in the elasticity matrix (the D matrix) based on Equation 1. A Plasticity module was brought into the Linear Elastic Material module by utilizing a user-defined yield surface where the Effective stress is defined as $\operatorname{sqrt}($ solid.II $2 s) * \rho\left(\theta^{\prime}\right)-\alpha *(-$ solid.I1s) and the Initial yield stress can be 
defined as $\kappa$ based on Equation 3. A user-defined Plastic potential $(\boldsymbol{Q})$ is defined as $\operatorname{sqrt}($ solid.II $2 s) * \rho\left(\theta^{\prime}\right)-\beta *(-$ solid.I1s) according to Equation 11 . Note that the $\alpha$ and $\beta$ are defined in Step 1 as Parameters using Equations 7 and 8. $\rho\left(\theta^{\prime}\right)$ is defined as a Variable using Equation 5.

\section{Finite Element Model of Flexible Pavement Structure}

A pavement structure shown in Figure 1 was modeled as an axisymmetric structure in Comsol Multiphysics program with a width of $120 \mathrm{~cm}$ and three layers including an asphalt course of $15 \mathrm{~cm}$, a UGB base course of $25 \mathrm{~cm}$ and a subgrade of $140 \mathrm{~cm}$. A ramp load was applied in $0.05 \mathrm{~s}$ on a circular loading area with a radius of $15 \mathrm{~cm}$. Three load levels were tested, including 566, 755 and $1006 \mathrm{kPa}$. The mesh of the model used a resolution of $1.875 \mathrm{~cm}$ and a biased mesh distribution was used, as shown in Figure 1. The dimension and loading conditions were selected to simulate the asphalt pavement structure and the applied load used in a laboratory large-scale tank test, the results of which are employed to validate the finite element model predictions. The material properties and model coefficients are shown in Table 2.

\section{MODEL VALIDATION AND RESULT DISCUSSIONS Model Validations by Large-scale Tank Test}

To validate the finite element models (FEM) of the UGB in the flexible pavement, surface deflections and vertical stresses at different locations in base and subgrade were measured in the large-scale tank test. The testing procedure and measurement details of the large-tank test are described elsewhere (27). Figure 2a compares the FEM surface deflection predictions using the nonlinear anisotropic elastoplastic (NAEP) UGB model with the measured values at different distances $(0,30,60,90$ and $110 \mathrm{~cm})$ from the loading center under the three loading levels. It is seen that the FEM predicted surface deflections increased with loading level and matched with the measured surface deflections in general, which demonstrates the robustness of the NAEP model. The measured surface deflections at the loading center $(\mathrm{R}=0)$ under all three loading levels are greater than that predicted by FEM, which could be due to that a dynamic load was used in the test while a quasi-static ramp load was used in FEM simulations. The dynamic loading effect may need to be considered in a future FEM simulation.

Figures $2 b, 2 c$ and $2 d$ compare the vertical stresses at different depths $(Z=-21.25 \mathrm{~cm}$ in base, $-33.75 \mathrm{~cm}$ in base and $-55 \mathrm{~cm}$ in subgrade) and two distances from loading $(\mathrm{R}=0$ and $15 \mathrm{~cm})$ under three load levels, respectively. It is observed that the FEM predicted vertical stresses are all in compression (a negative stress is in compression) and decrease with depth, which are consistent with the measured vertical stresses. The FEM predicted vertical stresses at the distance of $\mathrm{R}=15 \mathrm{~cm}$ matched well with the laboratory measurements, while those at the loading center $(\mathrm{R}=0)$ depart from the measured stresses. For instance, the measured vertical stresses in subgrade $(Z=-55 \mathrm{~cm})$ and at loading center $(R=0)$ are always less than that predicted from FEM, which was also observed previously (27). This may be caused by soil arching effect over the pressure sensor during construction or not accounting for the stress-dependent behavior for soil subgrade in the FEM simulations. Nevertheless, the FEM results are in good agreement with the large-scale tank test measurements in general. The proposed nonlinear anisotropic elastoplastic model and the weak form equation-based FEM techniques are valid and effective in predicting accurate responses of the UGB materials in flexible pavements.

\section{Pavement Response Analysis using Different UGB Models}

Further analysis based on the validated finite element models is conducted to obtain the pavement responses using different UGB models including nonlinear anisotropic elastoplastic (NAEP) model, nonlinear anisotropic elastic (NAE) model and linear anisotropic elastic (LAE) model. Figures 3a, 3b and $3 \mathrm{c}$ show the distribution of the horizontal stresses at load centerline along base course depth with increasing load levels predicted using LAE, NAE and NAEP models, respectively. Figure 3a illustrates 
that, when LAE model is used for UGB, the horizontal stress is mainly in tension (in positive) and increases with depth and load level. Note that if a linear isotropic elastic (LIE) model is used, the maximum tensile horizontal stress will become even higher (e.g., $50 \mathrm{kPa}$ ), the distribution of which is not shown here but similar to that in Figure 3a.

The high tensile stress at the base course bottom predicted by LAE or LIE model is unexpected as UGB has a very limited tensile strength. The high tensile stress can be substantially reduced when a stressdependent anisotropic modulus model is used for the base course as indicated from the literature (4). The same conclusion is derived from Figure $3 \mathrm{~b}$ that, using an NAE model, the horizontal stresses are reduced and vary from compression to tension as load level increases. The tensile horizontal stress values ( 7 to 10 $\mathrm{kPa}$ at the load level of $755 \mathrm{kPa}$ ) and its decreasing distribution along depth are consistent with the findings from the literature, in which it is explained that the tensile horizontal stresses are accommodated by compressive residual stresses (about $21 \mathrm{kPa}$ ) due to compaction $(4,13)$.

The compressive compensation from the compaction-induced residual stresses is valid, however, it may be insufficient to ensure that the base course is always in compression especially when the load level goes higher. For example, Figure $3 \mathrm{~b}$ shows that the horizontal stress became as high as $25 \mathrm{kPa}$ when the load level reached $1006 \mathrm{kPa}$. It could go higher when the load level kept increasing when the NAE model is used. However, this cannot happen in the field reality. The UGB materials will have been yielded and plastic deformation will occur before the vertical stress reaches $250 \mathrm{kPa}$ in compression (seen from Figure 2d) while the horizontal stress is $25 \mathrm{kPa}$ in tension. The plastic deformation in the base course will lead to an altered stress distribution.

Figure $3 \mathrm{c}$ shows the horizontal stress distribution in the base course when the nonlinear anisotropic elastoplastic (NAEP) model is used for the UGB. The horizontal stresses at the base bottom were further reduced (to be less than $10 \mathrm{kPa}$ ) compared to that calculated by the NAE model $(25 \mathrm{kPa})$. This low tensile stresses can be fully compensated by the compaction-induced compressive residual stresses or sustained by suction-related tensile strength. Sensitivity analysis indicates that a thicker asphalt course or a higher asphalt modulus will also further reduce this horizontal tensile stress or even produce a completely compressive horizontal stress in the base course. Sensitivity analysis also shows that this tensile stress is hardly increased under a higher load due to the UGB's saturated plastic hardening. That means a further higher load will not lead to a significant increase of the bottom tensile stress but result in an over-stress softening and final failure of the UGB material, which is out of the modelling scope of this study but will be modeled in a future study. Figure $4 \mathrm{c}$ also shows that the horizontal stress from the middle to the top along the centerline of the base became compression, which will be explained using the plastic strain and horizontal displacement presented in Figure 4.

Figure 4a shows the plastic strains occurring from the middle to the top of the base course when the NAEP model was used. The high plastic strains lead to a significant horizontal displacement (dilation) as shown in Figure 4b. This expansive deformation in the horizontal direction has been constrained by the surrounding UGB materials, resulting in an increase of the confining pressures that is in compression and produced by the surrounding UGB material. This compressive confining pressure leads to a reduction of the horizontal tensile stress at base course bottom and an increase of the horizontal compressive stress from the middle to the top of the base course. Note that the horizontal dilation is more significant and the induced confining pressure is higher in the middle and top of the base course (due to higher plastic strain) than that at the bottom of the base course. Therefore the horizontal stress became compression in the middle and top of the base course compensated by the higher confining pressure while still remained in tension resulting from less confining pressure at the bottom of the base course.

In comparison, the horizontal displacement predicted by the NAE model (shown in Figure 4c) was much smaller than (only 1/1400 of) that predicted by the NAEP model (shown in Figure 4b). Therefore little horizontal dilation occurred and no confining effect was introduced in the base course when the NAE 
model (no plastic component) was used, which leads to unreasonably high tensile stress in the horizontal direction of the base course.

The significant horizontal displacement shown in Figure $4 \mathrm{~b}$ also explains an experimental finding from the authors' previous study (27), i.e., placing the geogrid in the middle of the base course is much more effective in reducing the rutting damage of the base course than placing the geogrid at the bottom of the base course. The high plastic strain on the base top and the significant horizontal displacement in the base middle may have been effectively constrained and reduced by placing the geogrid in the middle of the base course. Placing the geogrid at the base bottom cannot effectively limit the plastic strain occurring mainly in the top area of the base course. This explanation will be further verified in a continuing NAEP modelling of the UGB material by including the geogrid in base course.

Figure $5 \mathrm{a}$ and $5 \mathrm{~b}$ present the distribution of the stress-dependent modulus determined by NAEP model and the NAE model, respectively. Both show the highest modulus on the top center area of the base course and a decreasing modulus with base depth and the distance to the load centerline. The results are consistent with that obtained in the literature $(4,6)$. However, compared to the modulus obtained from the NAE model (Figure 5b), the NAEP model predicted a higher modulus for the base course (Figure 5a). This is due to that the NAEP predicts less horizontal tensile stresses and more compressive stresses as indicated Figure $3 \mathrm{c}$, leading to a higher $I_{l}$ and lower $\tau_{o c t}$ and eventually a higher modulus according to Equation 2.

\section{Effect of UAB Models on Critical Pavement Responses}

Table 3 compares the critical pavement responses predicted by LAE, NAE and NAEP models, including the tensile strain at bottom of asphalt course, the average vertical compressive strain in the base course and the compressive strain in the top of the subgrade. It is evident that at all load levels the linear anisotropic model (LAE) under-predicted the critical pavement responses compared to the nonlinear models (NAE and NAEP). When the stress-dependent anisotropic modulus was considered for the UGB, the elastic model (NAE) predicted the same asphalt bottom tensile strain as that calculated by the plastic model (NAEP). However, the NAE model predicted higher the average compressive strain in the base course and lower compressive strain on the top of subgrade compared to the NAEP model. The prediction difference between the two models became more significant when the load level increased. The lower compressive strain in base course obtained by NAEP model was caused by the higher modulus of the UGB materials when plasticity is considered, as shown in Figure 5a. The higher compressive strain in the top of subgrade when NAEP model was used for UGB is due to that higher stress was introduced in subgrade when plastic deformation occurs in base course. One can conclude that the including plasticity with a nonlinear anisotropy for UGB alter the pavement responses in base and subgrade of a flexible pavement.

Furthermore, since a lower tensile strain at asphalt bottom leads to a longer fatigue life and a lower subgrade top compressive strain results in less rutting damage. It may conclude that the linear anisotropic base model will riskily over-predict the fatigue life and under-predict the rutting damage in asphalt pavements. The nonlinear anisotropic elastic base model will result in the same fatigue life for asphalt course as the nonlinear anisotropic elastoplastic base model, but it will riskily under-predict the rutting damage in the pavements. Thus a complete nonlinear (stress-dependent) anisotropic elastoplastic model is required for accurately modelling the UGB material in the base course.

Future research continuing from this study includes evaluating the effects of a dynamic load and a repeated load on the pavement responses and performance using the nonlinear anisotropic elastoplastic model. Further studies are also needed to predict the moisture diffusion in the pavement structure and couple the moisture effect into the nonlinear anisotropic elastoplastic model for the UGB materials. 


\section{SUMMARY AND CONCLUSIONS}

1) A nonlinear stress-dependent anisotropic elastoplastic model was developed for unbound granular base materials and successfully implemented in a weak form equation-based finite element program. A laboratory large-scale tank pavement loading test was used to validate the model using measured surface deflections and the vertical stresses in base and subgrade, proving that the model is valid and effective in predicting accurate responses of the unbound granular base materials in flexible pavements.

2) The nonlinear anisotropic elastoplastic model predicted less horizontal tensile stresses at the base bottom and introduced compressive stresses in the middle and the top of the base course. This is caused by an increasing confinement resulting from a horizontal plastic dilation in the base course, which cannot be modeled by a nonlinear anisotropic elastic model. This also explains a laboratory finding that placing the geogrid in the middle of the base course is much more effective in reducing rutting than placing the geogrid at the base bottom.

3) The stress-dependent modulus for the unbound granular material in base course decreases with base depth and the distance from loading centerline. The nonlinear anisotropic elastoplastic model predicted higher modulus in the base course than the nonlinear anisotropic elastic model.

4) A linear anisotropic base model will riskily over-predict fatigue life and under-predict the rutting damage of flexible pavements. The nonlinear anisotropic elastic base model will result in the same fatigue life as the nonlinear anisotropic elastoplastic base model, but it will riskily underpredict the rutting damage. Therefore the nonlinear (stress-dependent) anisotropic elastoplastic model is required for accurately predicting the performance of the unbound granular base material in asphalt pavements.

\section{ACKNOWLEDGEMENT}

Special thanks from the authors are given to Professor. Raj V Siddharthan and Professor Elie Hajj from the University of Nevada, Reno for providing valuable measuring data from the large-scale tank pavement tests for model validation.

\section{REFERENCES}

1. Tutumluer, E. and U. Seyhan. Laboratory Determination of Anisotropic Aggregate Resilient Moduli Using an Innovative Test Device. Transportation Research Record: Journal of the Transportation Research Board, Vol. 1687, No. 1999, pp. 13-21.

2. Adu-Osei, A., D. Little, and R. Lytton. Cross-Anisotropic Characterization of Unbound Granular Materials. Transportation Research Record: Journal of the Transportation Research Board, Vol. 1757, No. 2001, pp. 82-91.

3. Gu, F., H. Sahin, X. Luo, R. Luo, and R.L. Lytton. Estimation of Resilient Modulus of Unbound Aggregates Using Performance-Related Base Course Properties. Journal of Materials in Civil Engineering, Vol. 27, No. 6, 2015, pp. 04014188.

4. Tutumluer, E. and M.R. Thompson. Anisotropic Modeling of Granular Bases in Flexible Pavements. Transportation Research Record: Journal of the Transportation Research Board, Vol. No. 1997, pp. 18-26.

5. Oh, J.-H., R.L. Lytton, and E.G. Fernando. Modeling of Pavement Response Using Nonlinear Cross-Anisotropy Approach. Journal of Transportation Engineering, Vol. 132, No. 6, 2006, pp. 458-468.

6. Al-Qadi, I.L., H. Wang, and E. Tutumluer. Dynamic Analysis of Thin Asphalt Pavements by Using Cross-Anisotropic Stress-Dependent Properties for Granular Layer. Transportation Research Record: Journal of the Transportation Research Board, Vol. 2154, No. 2010, pp. 156-163.

7. Tutumluer, E., D. Little, and S.-H. Kim. Validated Model for Predicting Field Performance of Aggregate Base Courses. Transportation Research Record: Journal of the Transportation Research Board, Vol. 1837, No. 2003, pp. 41-49. 
8. Wang, H. and I.L. Al-Qadi. Importance of Nonlinear Anisotropic Modeling of Granular Base for Predicting Maximum Viscoelastic Pavement Responses under Moving Vehicular Loading. Journal of Engineering Mechanics, Vol. 139, No. 1, 2013, pp. 29-38.

9. Uzan, J. Permanent Deformation of a Granular Base Material. Transportation Research Record: Journal of the Transportation Research Board, Vol. 1673, No. 1999, pp. 89-94.

10. Chazallon, C., P. Hornych, and S. Mouhoubi. Elastoplastic Model for the Long-Term Behavior Modeling of Unbound Granular Materials in Flexible Pavements. International Journal of Geomechanics, Vol. 6, No. 4, 2006, pp. 279-289.

11. Gu, F., Y. Zhang, C.V. Droddy, R. Luo, and R.L. Lytton. Development of a New Mechanistic Empirical Rutting Model for Unbound Granular Material. Journal of Materials in Civil Engineering, Vol. 28, No. 8, 2016, pp. 04016051.

12. Lai, M., E. Krempl, and D. Ruben, Introduction to Continuum Mechanics. Elsevier Inc., Burlington, MA, USA, 2010.

13. Uzan, J. Characterization of Granular Material. In Transportation Research Record, TRB, National Research Council, Washington, D.C., 1985, pp. 52-59.

14. Zhang, Y., M. Bernhardt, G. Biscontin, R. Luo, and R. Lytton. A Generalized Drucker-Prager Viscoplastic Yield Surface Model for Asphalt Concrete. Materials and Structures, Vol. 48, No. 11, 2014, pp. 3585-3601.

15. Tashman, L., E. Masad, D. Little, and H. Zbib. A Microstructure-Based Viscoplastic Model for Asphalt Concrete. International Journal of Plasticity, Vol. 21, No. 9, 2005, pp. 1659-1685.

16. Oda, M. and H. Nakayama. Yield Function for Soil with Anisotropic Fabric. Journal of Engineering Mechanics, Vol. 115, No. 1, 1989, pp. 89-104.

17. Zhang, Y., R. Luo, and R.L. Lytton. Microstructure-Based Inherent Anisotropy of Asphalt Mixtures. Journal of Materials in Civil Engineering, Vol. 23, No. 10, 2011, pp. 1473-1482.

18. Masad, E., D. Little, and R. Lytton. Modeling Nonlinear Anisotropic Elastic Properties of Unbound Granular Bases Using Microstructure Distribution Tensors. International Journal of Geomechanics, Vol. 4, No. 4, 2004, pp. 254-263.

19. ASTM. Standard Test Method for California Bearing Ratio of Laboratory-Compacted Soils. D1883-14, West Conshohocken, PA, 2014.

20. Zhang, Y., R. Luo, and R.L. Lytton. Characterizing Permanent Deformation and Fracture of Asphalt Mixtures by Using Compressive Dynamic Modulus Tests. Journal of Materials in Civil Engineering, Vol. 24, No. 7, 2012, pp. 898-906.

21. ASTM. Standard Test Method for Dynamic Modulus of Asphalt Mixtures. D3497-79, West Conshohocken, PA, 2003.

22. Zhang, Y., B. Birgisson, and R.L. Lytton. Weak Form Equation-Based Finite-Element Modeling of Viscoelastic Asphalt Mixtures. Journal of Materials in Civil Engineering, Vol. No. 2015, pp. 04015115.

23. Zhang, Y., R. Luo, and R.L. Lytton. Anisotropic Viscoelastic Properties of Undamaged Asphalt Mixtures. Journal of Transportation Engineering, Vol. 138, No. 1, 2012, pp. 75-89.

24. TxDOT. Test Procedure for Triaxial Compression for Disturbed Soils and Base Materials. Texas Department of Transportation (TxDOT), Austin, TX, 2010.

25. Gu, F., Y. Zhang, X. Luo, R. Luo, and R.L. Lytton. Impact of Geogrid on Cross-Anisotropy and Permanent Deformation of Unbound Granular Materials. Transportation Research Record: Journal of Transportation Research Record, Vol. 2580, No. 2016.

26. Zhang, Y., F. Gu, B. Birgisson, and R.L. Lytton. Viscoelasticplastic-Fracture Modeling of Asphalt Mixtures under Monotonic and Repeated Loads. Transportation Research Record: Journal of Transportation Research Record, Vol. 2631, No. 2017, pp. 20-29.

27. Gu, F., X. Luo, R. Luo, R.L. Lytton, E.Y. Hajj, and R.V. Siddharthan. Numerical Modeling of Geogrid-Reinforced Flexible Pavement and Corresponding Validation Using Large-Scale Tank Test. Construction and Building Materials, Vol. 122, No. 2016, pp. 214-230. 


\section{LIST OF TABLES}

TABLE 1 Pavement Structures, Material Models, Parameters and Characterization Tests

TABLE 2 Model Parameters for Asphalt Concrete, UGB and Subgrade

TABLE 3 Predicted Critical Pavement Responses by Different UGB Models 


\section{LIST OF FIGURES}

FIGURE 1 Axisymmetric finite element model of an asphalt pavement structure in a large-scale tank test.

FIGURE 2 Validation of finite element modelling (FEM) by surface deflections and vertical stresses measured in large-scale tank tests of an asphalt pavement structure.

FIGURE 3 Horizontal stresses ( $\mathrm{kPa}$ ) at loading center along depth in base course with increasing load levels where (3a) linear anisotropic elastic (LAE) model, (3b) nonlinear anisotropic elastic (NAE) model and (3c) nonlinear anisotropic elastoplastic (NAEP) model were used for UGB (Tension is positive).

FIGURE 4 Contour of plastic strain $(\mu \varepsilon)$ and horizontal displacement $(\mu \mathrm{m})$ in base course at a load level of $1006 \mathrm{kPa}$ where (4a and 4b) nonlinear anisotropic elastoplastic (NAEP) model and (4c) nonlinear anisotropic elastic (NAE) model were used for UGB.

FIGURE 5 Contour of stress-dependent modulus (MPa) in base course at a load level of $1006 \mathrm{kPa}$ where (5a) nonlinear anisotropic elastic (NAE) model and (5b) nonlinear anisotropic elastoplastic (NAEP) model were used for UGB. 
TABLE 1 Pavement Structures, Material Models, Parameters and Characterization Tests

\begin{tabular}{|c|c|c|c|c|}
\hline $\begin{array}{l}\text { Pavement Layers } \\
\text { (thickness) }\end{array}$ & Materials & Constitutive Models & $\begin{array}{l}\text { Model } \\
\text { Parameters }\end{array}$ & Laboratory Test \\
\hline $\begin{array}{l}\text { Layer } 1 \\
(15 \mathrm{~cm})\end{array}$ & $\begin{array}{l}\text { Asphalt } \\
\text { concrete }\end{array}$ & Viscoelastic & $E_{\infty}, v_{0}, E_{i}, \tau_{i}$ & Dynamic modulus test \\
\hline $\begin{array}{l}\text { Layer } 2 \\
(25 \mathrm{~cm})\end{array}$ & $\begin{array}{l}\text { Unbound } \\
\text { granular } \\
\text { base }\end{array}$ & $\begin{array}{l}\text { a) Linear Anisotropic } \\
\text { Elastic (LAE) } \\
\text { b) Nonlinear Anisotropic } \\
\text { Elastic (NAE) } \\
\text { c) Nonlinear Anisotropic } \\
\text { Elastoplastic (NAEP) }\end{array}$ & $\begin{array}{l}k_{1}, k_{2}, k_{3} \\
n, m, v_{z x}, v_{x y}, \\
C, \phi\end{array}$ & 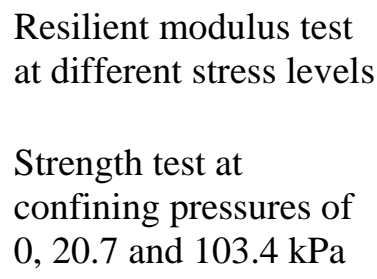 \\
\hline $\begin{array}{l}\text { Layer } 3 \\
(140 \mathrm{~cm})\end{array}$ & Subgrade & Elastic & $\begin{array}{l}\text { Young's } \\
\text { modulus }\end{array}$ & $\begin{array}{l}\text { California bearing ratio } \\
\text { test }\end{array}$ \\
\hline
\end{tabular}


TABLE 2 Model Parameters for Asphalt Concrete, UGB and Subgrade

Asphalt Concrete (long term equilibrium modulus $E_{\infty}=42 \mathrm{MPa}$, Poisson's ratio $v_{0}=0.35$ )

\begin{tabular}{|c|c|c|c|c|c|c|c|c|c|c|}
\hline$t$ & 1 & \multicolumn{2}{|l|}{2} & \multicolumn{2}{|l|}{3} & \multicolumn{2}{|l|}{4} & 5 & \multicolumn{2}{|l|}{6} \\
\hline$E_{i}(M P a)$ & 6564 & \multicolumn{2}{|c|}{6582} & \multicolumn{2}{|l|}{3200} & \multicolumn{2}{|l|}{1342} & 299 & \multicolumn{2}{|c|}{103} \\
\hline$\tau_{i}(\mathrm{~s})$ & $4.09 \mathrm{E}-6$ & \multicolumn{2}{|c|}{$2.56 \mathrm{E}-4$} & \multicolumn{2}{|c|}{$7.71 \mathrm{E}-3$} & \multicolumn{2}{|c|}{$2.10 \mathrm{E}-1$} & $3.88 \mathrm{E}+0$ & \multicolumn{2}{|c|}{$6.63 \mathrm{E}+1$} \\
\hline \multicolumn{11}{|c|}{ Unbound Granular Base Materials } \\
\hline \multicolumn{2}{|c|}{ Material Models } & $k_{1}$ & $k_{2}$ & $k_{3}$ & $n$ & $m$ & $\overline{v z x}$ & $v_{x y}$ & $C(k P a)$ & $\phi\left(^{\circ}\right)$ \\
\hline \multicolumn{2}{|c|}{$\begin{array}{l}\text { a) Linear Anisotropic } \\
\text { Elastic (LAE) }\end{array}$} & \multicolumn{3}{|c|}{$\begin{array}{l}E_{z}=150 \mathrm{MPa} \text { is used by } \\
\text { averaging NAE results }\end{array}$} & 0.45 & 0.35 & 0.38 & 0.43 & NA & NA \\
\hline \multicolumn{2}{|c|}{$\begin{array}{l}\text { b) Nonlinear Anisotropic } \\
\text { Elastic (NAE) }\end{array}$} & 1281 & 0.81 & -0.08 & 0.45 & 0.35 & 0.38 & 0.43 & NA & NA \\
\hline \multicolumn{2}{|c|}{$\begin{array}{l}\text { c) Nonlinear Anisotropic } \\
\text { Elastoplastic (NAEP) }\end{array}$} & 1281 & 0.81 & -0.08 & 0.45 & 0.35 & 0.38 & 0.43 & 20.2 & 51.3 \\
\hline
\end{tabular}

Subgrade (Elastic modulus $E_{s}=69 \mathrm{MPa}$, Poisson ratio $v_{s}=0.4$ ) 
TABLE 3 Predicted Critical Pavement Responses by Different UGB Models

\begin{tabular}{lllll}
\hline Load Levels & UGB Model & $\begin{array}{l}\text { Tensile Strain }(\boldsymbol{\mu} \varepsilon) \\
\text { at Bottom of } \\
\text { Asphalt Course }\end{array}$ & $\begin{array}{l}\text { Average Vertical } \\
\text { Compressive strain } \\
(\boldsymbol{\mu} \boldsymbol{\varepsilon}) \text { along Base } \\
\text { Course Centerline }\end{array}$ & $\begin{array}{l}\text { Compressive Strain } \\
(\boldsymbol{\mu} \boldsymbol{\varepsilon}) \text { on Top of } \\
\text { Subgrade }\end{array}$ \\
\hline $566 \mathrm{kPa}$ & LAE & 274.1 & 514.4 & 604.4 \\
& NAE & 309.5 & 708.5 & 625.3 \\
& NAEP & 309.8 & 707.5 & 627.2 \\
$755 \mathrm{kPa}$ & LAE & 387.7 & 718.3 & 834.1 \\
& NAE & 421.3 & 888.8 & 876.5 \\
& NAEP & 422.6 & 870.7 & 911.8 \\
$1006 \mathrm{kPa}$ & LAE & 545.6 & 1000.1 & 1156.1 \\
& NAE & 564.9 & 1122.8 & 1217.1 \\
& NAEP & 568.2 & 1047.3 & 1317.8 \\
\hline
\end{tabular}




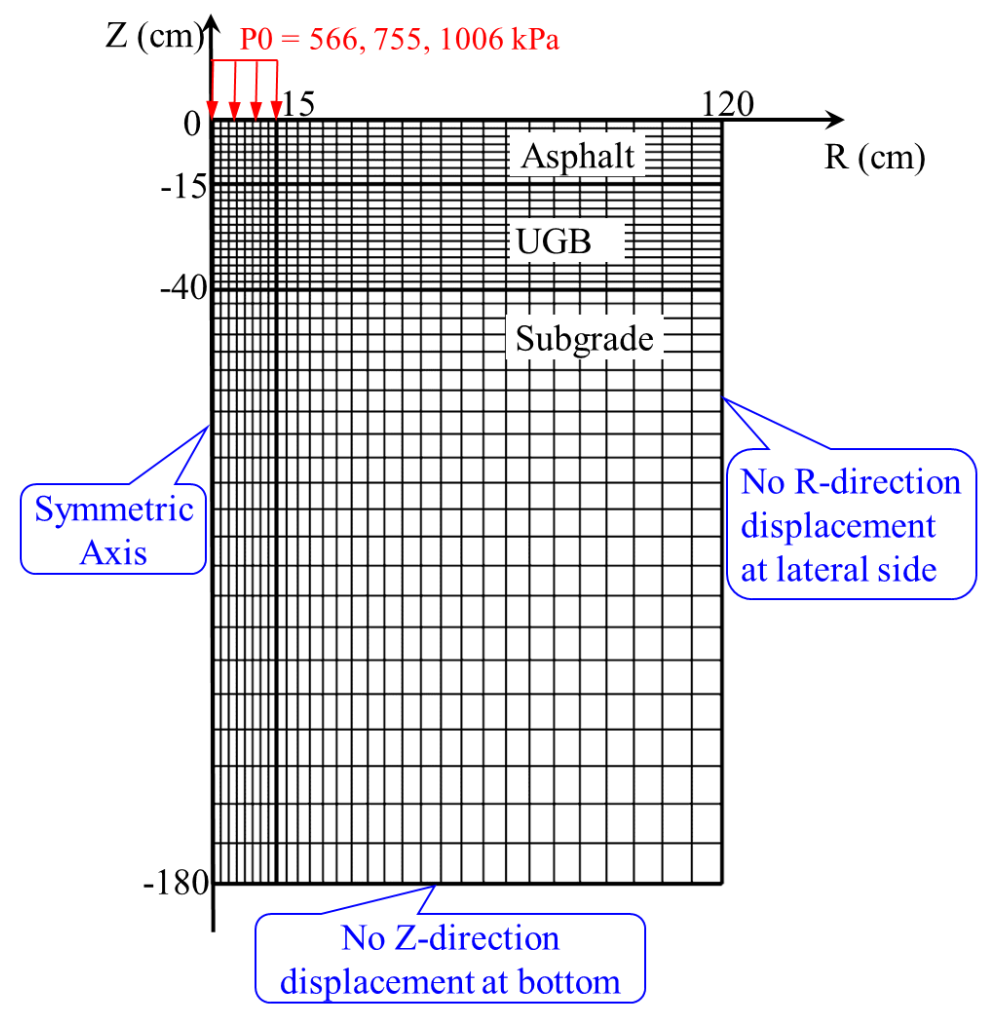

FIGURE 1 Axisymmetric finite element model of an asphalt pavement structure in a large-scale tank test. 


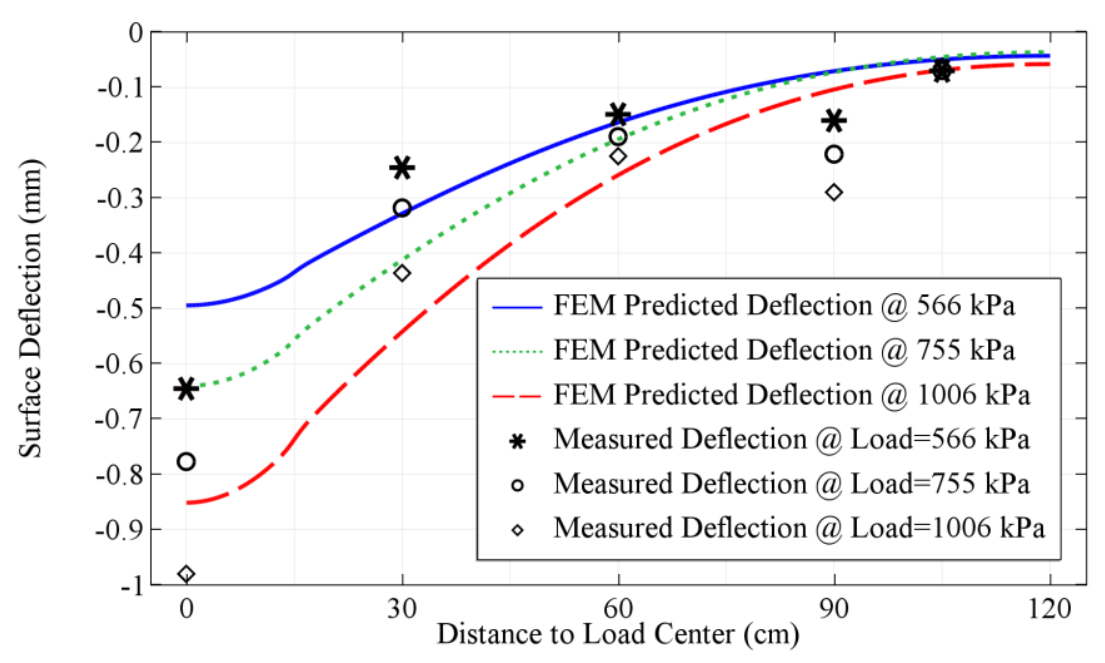

(2a) FEM validation by measured surface deflections

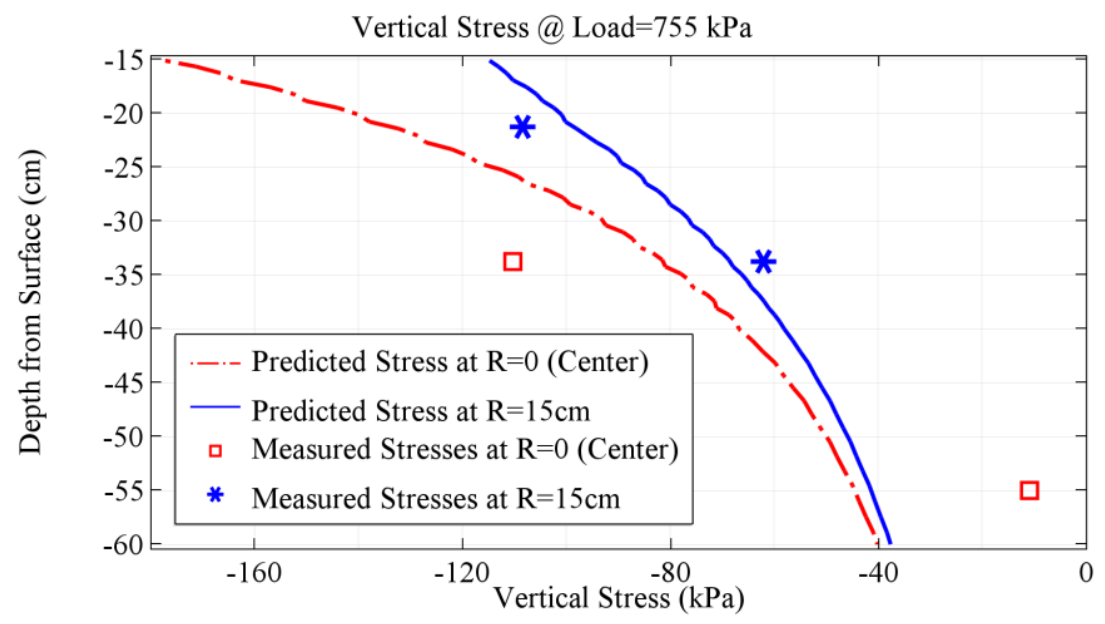

(2c) FEM validation of vertical stresses $(l o a d=755 \mathrm{kPa})$

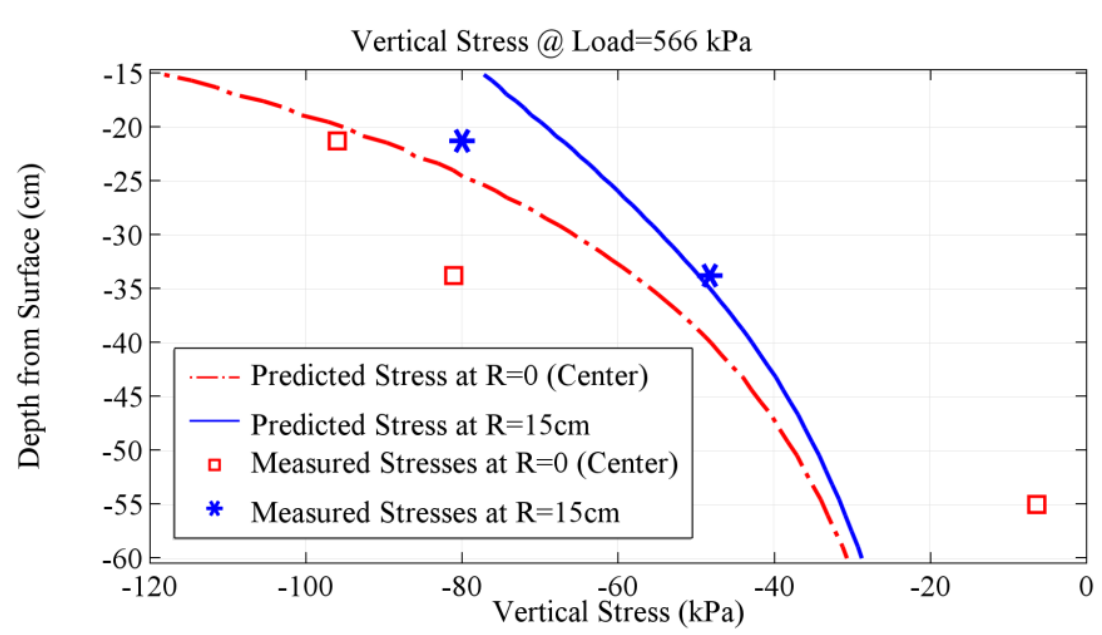

(2b) FEM validation of vertical stresses $(l o a d=566 \mathrm{kPa})$

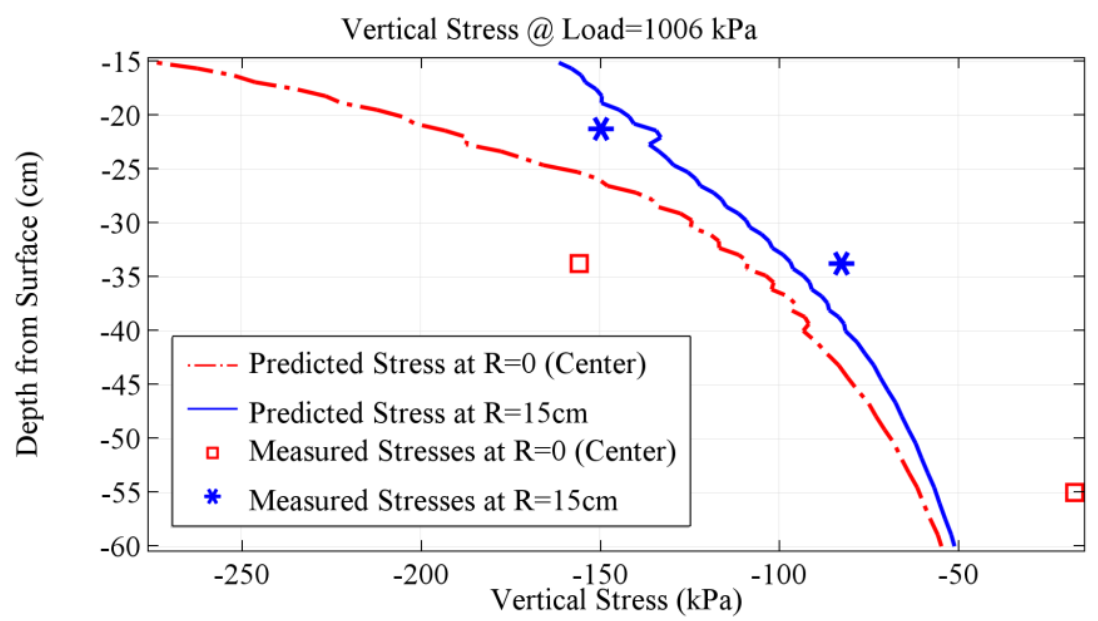

(2d) FEM validation of vertical stresses $(l o a d=1006 \mathrm{kPa})$

FIGURE 2 Validation of finite element modelling (FEM) by surface deflections and vertical stresses measured in large-scale tank tests of an asphalt pavement structure. 


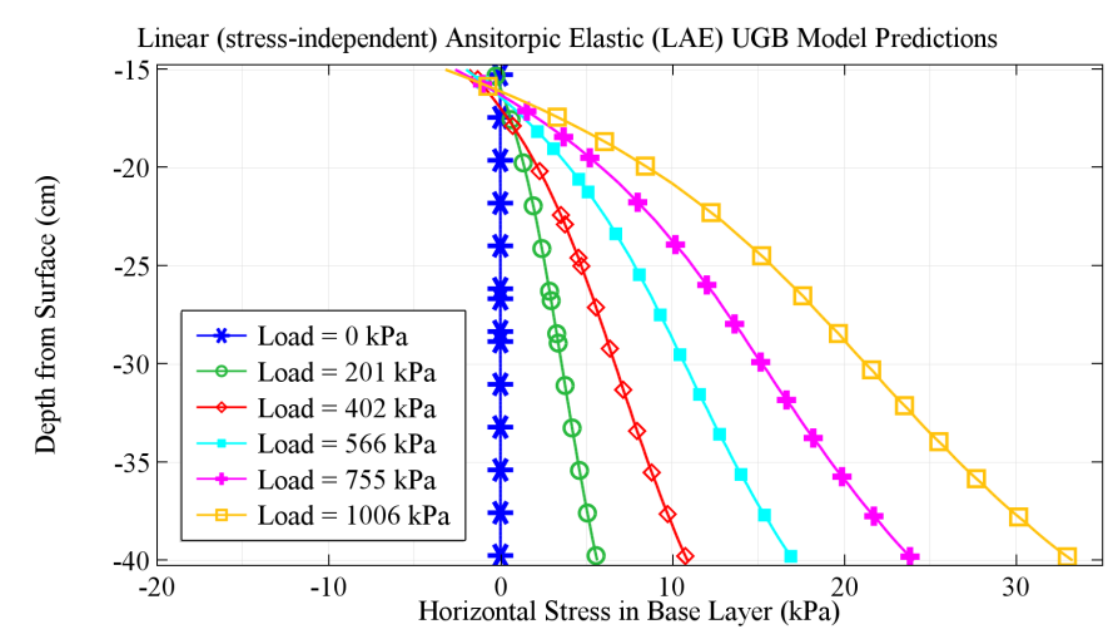

(3a) Horizontal stresses predicted by LAE model of UGB

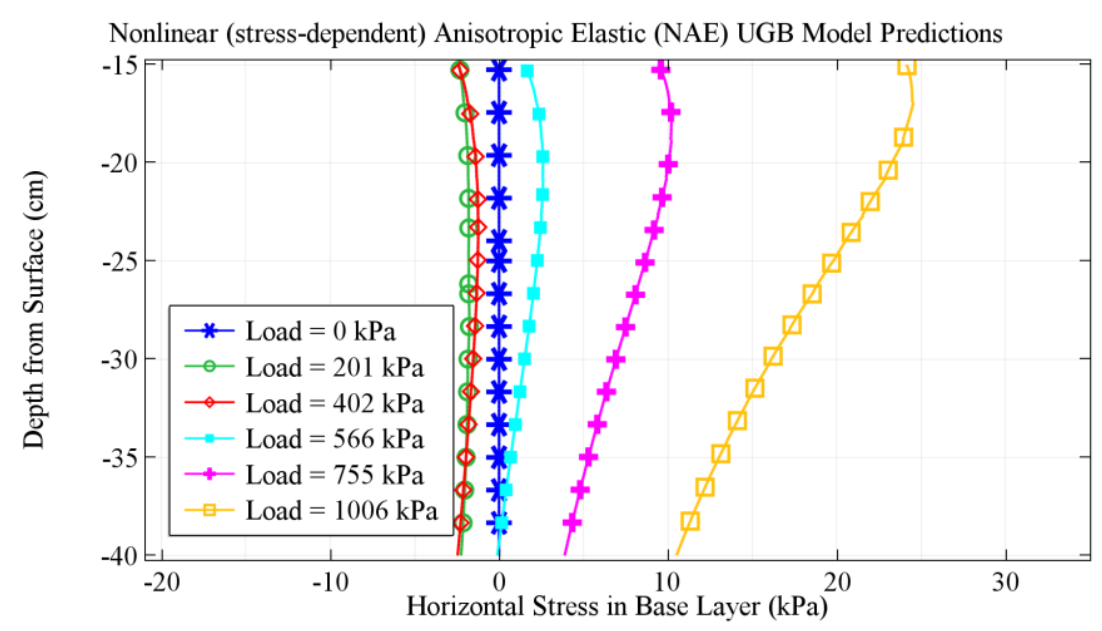

(3b) Horizontal stresses predicted by NAE model of UGB

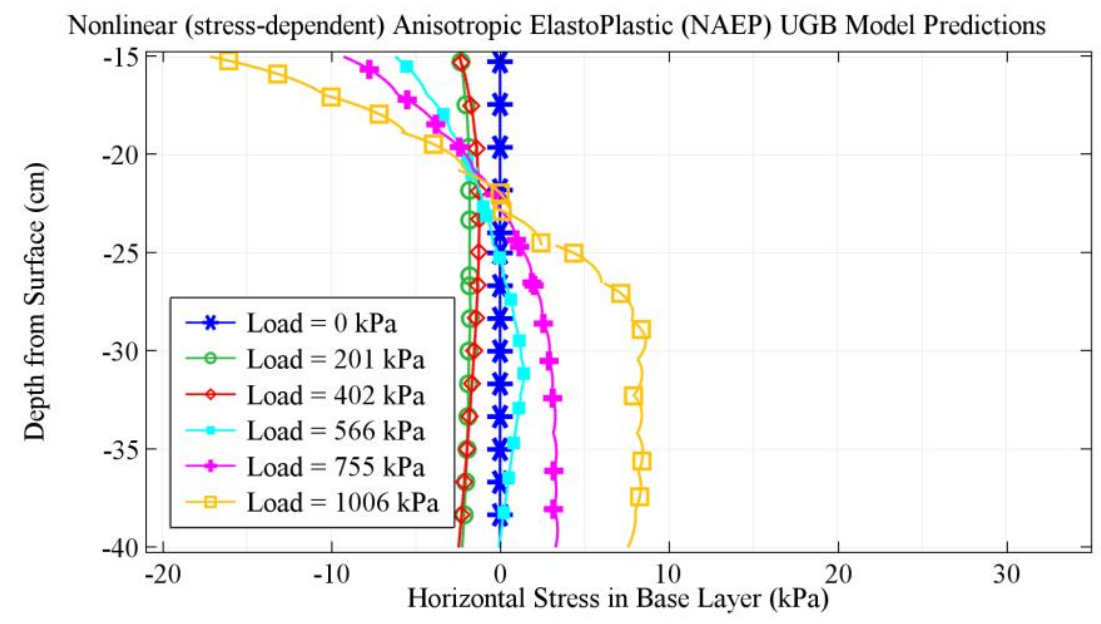

(3c) Horizontal stresses predicted by NAEP model of UGB

FIGURE 3 Horizontal stresses $(\mathrm{kPa})$ at loading center along depth in base course with increasing load levels where (3a) linear anisotropic elastic (LAE) model, (3b) nonlinear anisotropic elastic (NAE) model and (3c) nonlinear anisotropic elastoplastic (NAEP) model were used for UGB (Tension is positive). 

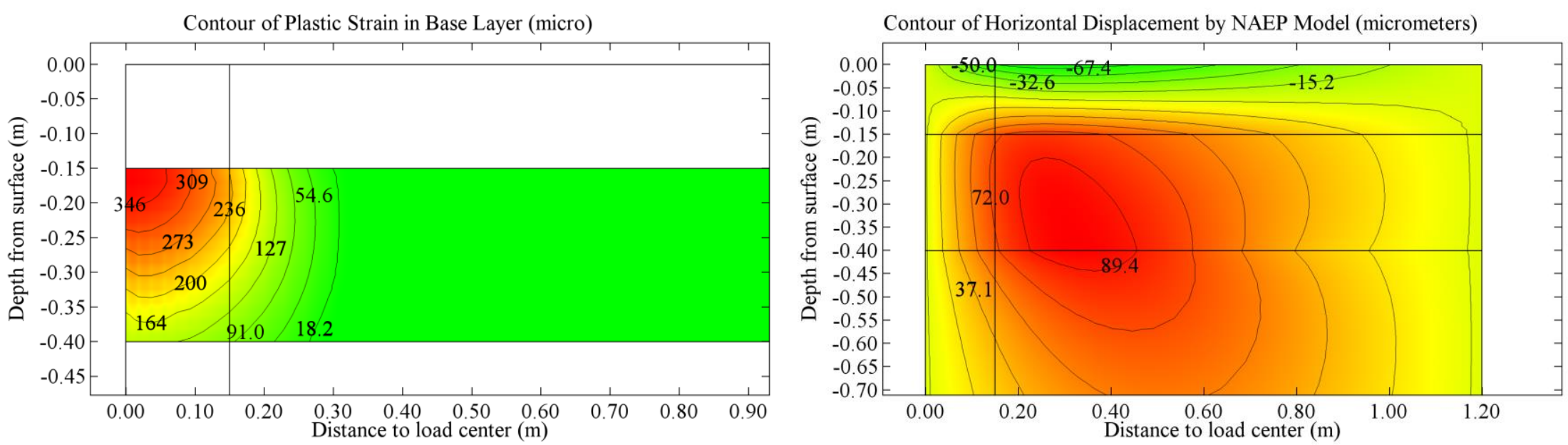

(4a) Plastic strain contour in base course by NAEP model

(4b) Horizontal displacement contour in base course by NAEP model

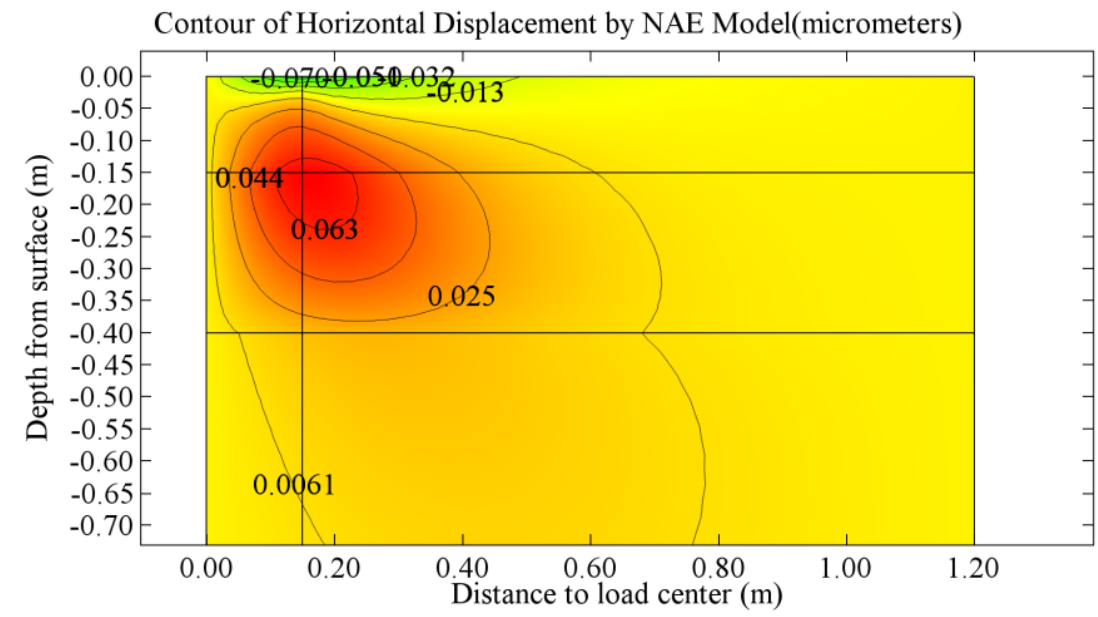

(4c) Horizontal displacement contour in base course predicted by NAE model

FIGURE 4 Contour of plastic strain $(\mu \varepsilon)$ and horizontal displacement $(\mu \mathrm{m})$ in base course at a load level of $1006 \mathrm{kPa}$ where $(4 \mathrm{a}$ and $4 \mathrm{~b})$ nonlinear anisotropic elastoplastic (NAEP) model and (4c) nonlinear anisotropic elastic (NAE) model were used for UGB. 


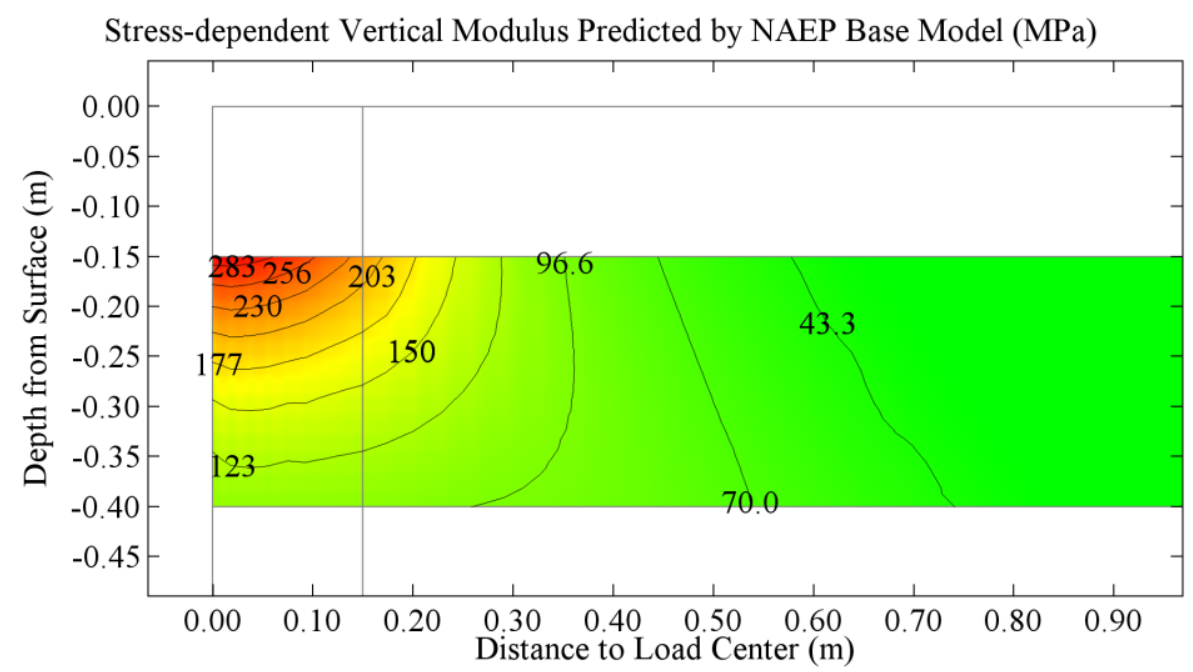

(5a) Modulus contour in base course predicted by NAEP model

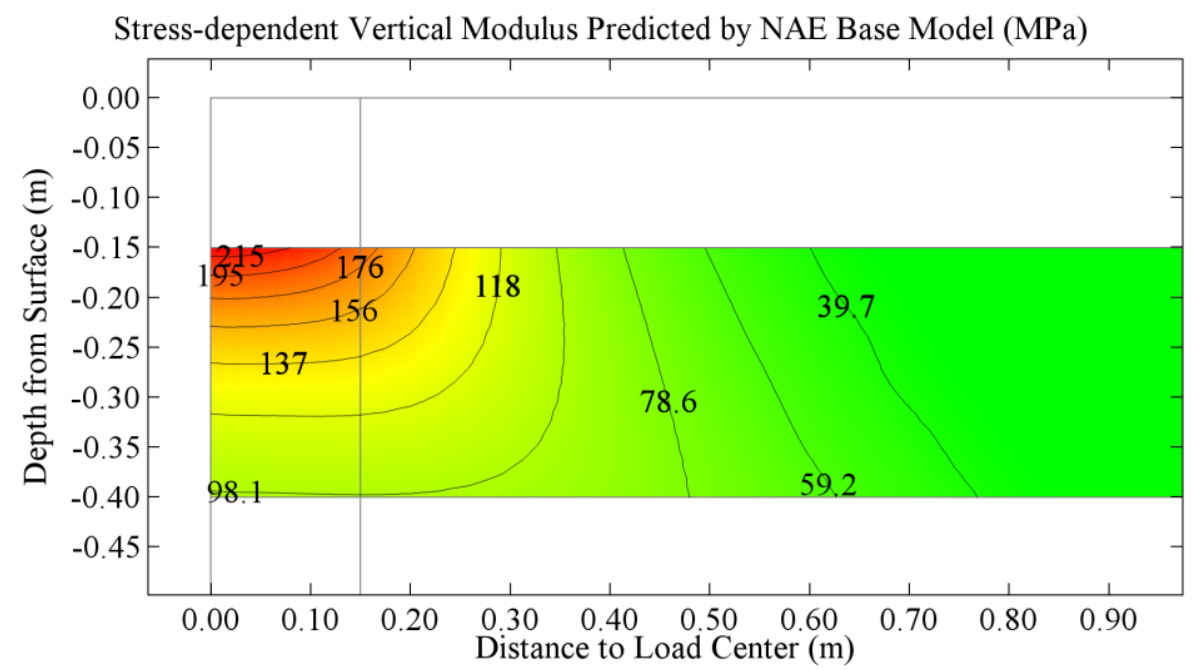

(5b) Modulus contour in base course predicted by NAE model

FIGURE 5 Contour of stress-dependent modulus (MPa) in base course at a load level of $1006 \mathrm{kPa}$ where (5a) nonlinear anisotropic elastic (NAE) model and (5b) nonlinear anisotropic elastoplastic (NAEP) model were used for UGB. 